\title{
Plug-in Hybrid Three-Wheeler Fueled with LPG-Ethanol Dual Injection
}

\author{
Bui Van Ga, Tran Thanh Hai Tung*, Bui Thi Minh Tu, Truong Le Bich Tram \\ Danang University of Science and Technology
}

\begin{abstract}
The paper presents the concept of a plug-in hybrid three-wheeler converted from a conventional gasoline motorcycle Honda RSX 110cc. The powertrain of the three-wheeler includes an internal combustion engine (ICE) driving the rear wheels and an electric motor driving the front wheel. The ICE is fueled with LPG-ethanol dual port injection. A microcontroller is set up connecting with the ECM of the original ICE for flexible adjustment of the ethanol/LPG ratio based on the gasoline injector control signal. The results show that the LPG-ethanol dual port injection forms a stratified octane number distribution at the end of the compression process. The relatively LPG-rich zone is found around the spark plug while the ethanol-rich zone is located near the cylinder wall. With the same throttle opening, when engine speed increases, to keep the equivalence ratio and ethanol/LPG rate unchanged, fuel injection time must be reduced. The reduction of the LPG injection time is, on average, faster than that of the ethanol injection time. A control system is designed for smooth combining use of the two power sources of the hybrid three-wheeler. In full load condition, the vehicle can run at maximum speed of $36 \mathrm{~km} / \mathrm{h}$ in electric motor operating $\operatorname{mode}$ and $70 \mathrm{~km} / \mathrm{h}$ in ICE mode. The vehicle acceleration time from 0 to $32 \mathrm{~km} / \mathrm{h}$ is $40 \mathrm{~s}$.
\end{abstract}

Keywords: Ethanol, LPG, Alternative fuels, Renewable energy, Plug-in hybrid motorcycle

\section{INTRODUCTION}

E-commerce is becoming more and more popular, especially during the Covid-19 pandemic. The service of goods delivery to the individual costumers plays an important role in this commerce mode. This service requires a compact, flexible means of transport. In this context, motorcycle is an effective solution. However, due to the E-commerce shipping vehicles often operate in crowded residential areas, narrow roads, and in the region where cars and trucks cannot reach, the pollution emissions control is strict requirements.

Many solutions for pollution emission control of motorcycles have been proposed. Battery electric motorcycle is an ideal solution, but it has some disadvantages such as low storage energy density, long recharging time, short cruising range...that limits its wide use in the practice. Application of alternative fuel such as CNG, LPG on ICE offers an effective way to reduce pollution emissions. The average $\mathrm{HC}$ and $\mathrm{CO}$ emissions of vehicles fueling with CNG can be $92 \%$ and $78 \%$ lower than that of gasoline, respectively [1]. However, bulky CNG tanks with high storage pressures is the main barriers to the wide application of this alternative fuel on motorcycles. LPG with low liquefaction pressure can overcome the disadvantages of CNG. LPG can be stored on board motorcycle in liquid state thus, energy storage density is improved significantly. LPG application on motorcycles has proven to be a suitable solution to reduce vehicle emissions [2-4].
Although CNG, LPG have advantages over other liquid fossil fuels in general, they produce the greenhouse gas $\mathrm{CO}_{2}$ during operation. Hence, the combining use of these alternative fuels and other renewable fuels will simultaneously reduce pollution emissions and greenhouse gas emission. Among renewable fuels, ethanol has many advantages such as high-octane number, high flame speed [5-7]. In addition, the presence of oxygen in ethanol promotes the complete combustion, improving engine efficiency and reducing emissions [8]. With these preeminent properties, ethanol is widely used as an additive to gasoline in many countries around the world.

In practice, ethanol is often in blend with gasoline for fueling the ICE. The high latent heat of the ethanol reduces the intake air temperature, thereby improving the engine's volumetric efficiency [9-10]. However, the high latent heat of ethanol leads to difficulty in starting gasoline-ethanol engines under low temperature condition. This is detrimental to a vehicle that frequently starts and stops, such as E-commerce shipping motorcycles. Using ethanol in combination with LPG instead of gasoline can overcome this inconvenience.

In fact, LPG can evaporate and diffuse in the air at a lower intake gas temperature than any liquid fuel. Therefore, the LPG engine can operate efficiently in any conditions, especially in urban operating condition. The pollution emission of the LPG engine is almost independent of the intake air temperature [11]. Compared to gasoline, the emissions of vehicles fueled with LPG are significantly reduced. In general, the $\mathrm{NO}_{\mathrm{x}}$ and $\mathrm{CO}$ emissions of LPG-fueled vehicles are, respectively, 20\% and $60 \%$ lower than those of gasoline-fueled vehicles [12]. Besides, when combining the use of LPG and ethanol, the high oxygen content in ethanol improves the burning rate, promotes complete combustion, so the $\mathrm{HC}$ and $\mathrm{CO}$ emissions in the exhaust gas decrease significantly compared to gasoline fueling mode [13-14]. According to Cetin [15], using a combination of $15 \%$ ethanol in the mixture with LPG is the most appropriate to reduce $\mathrm{CO}$ and $\mathrm{NO}_{\mathrm{x}}$ emissions. When the ethanol content is above this limit, $\mathrm{CO}$ emissions increase with engine speed [15]. When adding ethanol to LPG, the decrease in combustion temperature leads to a reduction in $\mathrm{NO}_{\mathrm{x}}$ emissions [15]. Therefore, the combining use of LPG and ethanol has been of interest to many scientists recently [16-17].

However, the effectiveness of LPG-ethanol on pollution emissions reduction is significant when the engine operates in relatively stable regime. For the engine of a vehicle delivering goods in a densely populated area, the effectiveness is limited. The reason is that the vehicle often needs great torque but low speed, particularly at starting regime. Therefore, the vehicle needs a supplementary power source. Combining LPG-ethanol engine with electric motor in hybrid mode is an effective 
solution. Electric motors have several advantages such as appropriate torque characteristic, without noise emission, and zero pollution emission while operating.

In this work, we study a plug-in hybrid three-wheel motorcycle fueled with LPG-ethanol converted from a traditional gasoline two-wheel motorcycle. The conversion includes the modification of the gasoline port injection system into LPG-ethanol dual fuel injection, addition of an electric motor power source and design of hybrid powertrain transmission system.

\section{MATERIAL AND METHOD}

\subsection{Retrofitted engine}

TAB. 1: ENGINE SPECIFICATIONS

\begin{tabular}{|l|l|}
\hline Motorcycle & Honda Wave Alfa RSX FI 110 \\
\hline Type of engine & 1 cylinder, 4 strokes, air cooling \\
\hline Bore x Stroke $(\mathrm{mm})$ & $50 \times 55.6$ \\
\hline Displacement $\left(\mathrm{cm}^{3}\right)$ & 109.1 \\
\hline $\begin{array}{l}\text { Maximum output power/speed } \\
\text { gasoline fueling mode }(\mathrm{kW} / \mathrm{rpm})\end{array}$ & $6.12 / 7500$ \\
\hline Compression ratio & $9: 1$ \\
\hline Fuel system & Gasoline port injection \\
\hline
\end{tabular}

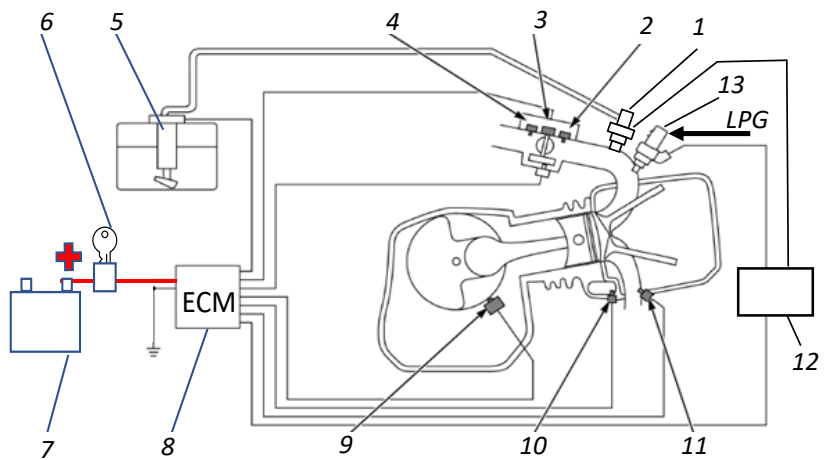

(a)

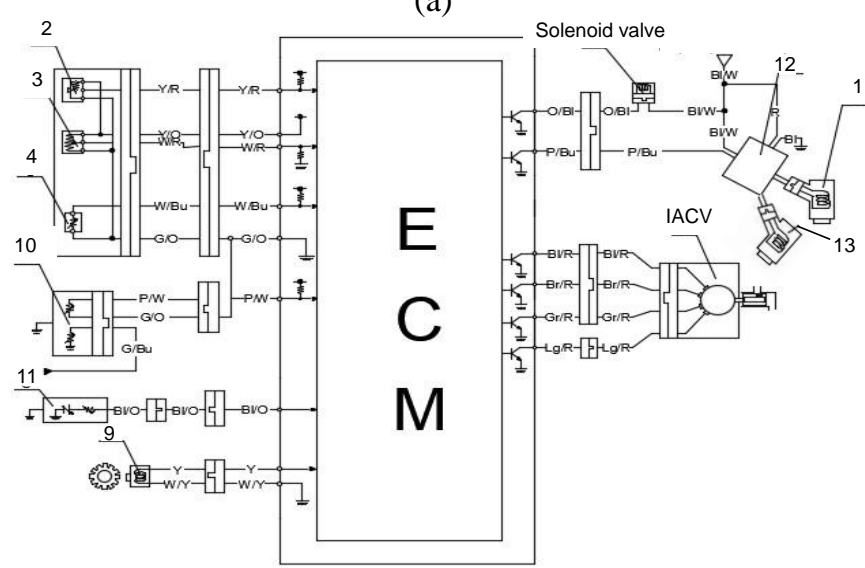

(b)

Fig. 1: Retrofitted ethanol-LPG dual fuel injection on Honda RSX engine: Sensor positions (a) and schema of circuit connection with ECM (b). 1. Ethanol injector, 2. Intake air pressure sensor (MAP), 3. Throttle position sensor (TP), 4. Intake air temperature sensor (IAT), 5. Fuel pump, 6. On/off switch, 7. Battery, 8. Electronic Control Unit, 9. crankshaft position sensor (CKP), 10. Engine oil temperature sensor (EOT), 11. Oxygen sensor, 12. Microcontroller Arduino, 13. LPG injector

In this study, a conventional gasoline 110cc Honda Wave 2-wheel motorcycle was converted into a plug-in hybrid 3wheel motorcycle fueled with LPG-ethanol. The specifications of the original engine are shown in Tab. 1.
The original Honda Wave 110cc motorcycle engine is gasoline port injection engine with PGM-FI (Programmed Fuel Injection) system. The amount of fuel injection is controlled by the ECM based on the signals given by the sensors. The set of sensors includes: intake air pressure sensor (MAP), throttle position sensor (TP), intake air temperature sensor (IAT), engine oil temperature sensor (EOT), crankshaft position sensor (CKP), and oxygen sensor. Fig. 1a shows the positions of the sensors on the engine. Thanks to these sensors, the injection time is adjusted according to the pressure and the temperature of air in the intake manifold, the engine speed, the cylinder temperature, the oxygen concentration in the exhaust gas.

The PGM-FI system is retrofitted to adopt the LPG-ethanol dual fuel injection. A gaseous LPG injector is located on the intake manifold just beside the ethanol injector which reused the original gasoline injector. The output signal of the ECM is the input of the microcontroller circuit instead of actuating the original gasoline injector. The signal is splitted into two channels with a given ratio of injection duration, one controls the ethanol injector and the other controls the LPG injector. The ratio of injection duration determines the proportion of fuel injected. It can be controlled automatically by the embedded program or by manual. The microcontroller used in this study is an Arduino UNO circuit board embedded a control program for ethanol and LPG injectors as shown in Fig. 1b.

TAB. 2: CHEMICAL AND PHYSICAL PROPERTIES OF ETHANOL, PROPANE AND BUTANE

\begin{tabular}{|l|c|c|c|}
\hline Fuel property & $\begin{array}{c}\text { Ethanol } \\
{[19]}\end{array}$ & $\begin{array}{c}\text { Propan } \\
{[20]}\end{array}$ & $\begin{array}{c}\text { Butan } \\
{[20]}\end{array}$ \\
\hline Formula & $\mathrm{C}_{2} \mathrm{H}_{5} \mathrm{OH}$ & $\mathrm{C}_{3} \mathrm{H}_{8}$ & $\mathrm{C}_{4} \mathrm{H}_{10}$ \\
\hline Molecular weight $[\mathrm{g} / \mathrm{mol}]$ & 46.07 & 44 & 58 \\
\hline Carbon [mass\%] & 52.2 & 82 & 83 \\
\hline Hydrogen [mass\%] & 13.1 & 18 & 17 \\
\hline Oxygen [mass\%] & 34.7 & 0 & 0 \\
\hline Liquid density $\left[\mathrm{kg} / \mathrm{m}^{3}\right]$ & 790 & 508 & 584 \\
\hline Boiling point $\left[{ }^{\circ} \mathrm{C}\right]$ & 78 & -42 & -0.5 \\
\hline Vapor pressure $[\mathrm{kPa}]$ at $38^{\circ} \mathrm{C}$ & 15.9 & 858.7 & 215.1 \\
\hline Specific heat $\left[\mathrm{kJ} \mathrm{kg}{ }^{-1} \mathrm{~K}^{-1}\right]$ & 2.4 & 1.63 & 1.675 \\
\hline Latent heat of vaporization $[\mathrm{kJ} / \mathrm{kg}]$ & 840 & 426 & 385 \\
\hline Low heating value $[\mathrm{MJ} / \mathrm{kg}]$ & 26 & 46.1 & 45.5 \\
\hline Autoignition temperature $\left[{ }^{\circ} \mathrm{C}\right]$ & 423 & 480 & 440 \\
\hline RON & 108.6 & 111 & 103 \\
\hline Stoichiometric air/fuel & 9 & 15.65 & 15.43 \\
\hline $\begin{array}{l}\text { Laminar flame velocity at } 100 \mathrm{kPa}, 325 \\
\text { K (cm/s) }\end{array}$ & 39 & 38 & 37 \\
\hline
\end{tabular}

\subsection{Simulation of $L P G$-ethanol dual injection}

The simulation of LPG-ethanol dual injection was carried out with help of the commercial Computational Fluid Dynamics (CFD) package ANSYS Fluent 18.2. The fundamental governing equations of fluid dynamics closed by the $\mathrm{k}-\varepsilon$ turbulence model. The 3D pressure based implicit unsteady solver available in ANSYS Fluent code is used to solve the basic governing equations. The equations are spatially discretized by means of the finite volume method using the STANDARD scheme for pressure interpolation. The discretization scheme for the convective term of transport equations used the first-order upwind scheme. The pressurevelocity coupling in the discretized equations is performed using the semi-implicit method for pressure linked equations (SIMPLE) algorithm to solve the pressure field. A similar 
simulation has been described in detail in our previous work [17-18]. The basic properties of considered fuels are shown in Tab. 2.

\section{RESULTS}

\subsection{LPG-Ethanol-air mixture formation}

Fig. 2 shows the distribution of liquid particle density and concentrations of ethanol and LPG in the cylinder when the engine operates at $5000 \mathrm{rpm}$, the throttle is completely open. The dual fuel injection ensures the general equivalence ratio $\phi$ $=1$ and the coefficient of equivalence ratio $\mathrm{k}=1$. The ethanol injector opens at $\varphi=20^{\circ} \mathrm{CA}$ and the LPG injector opens at $\varphi$ $=30^{\circ} \mathrm{CA}$. Ethanol exits the nozzle in the form of liquid fuel particles with small diameter, being swept up in the intake air and evaporating. It can be observed an area rich in ethanol vapor on the opposite side of the nozzle near the wall of intake manifold, while the high concentration of LPG is found near the injector. The density of liquid ethanol particles near the intake valve increases at the end of the injection phase and then decreases during the evaporation process. At $\varphi=140^{\circ} \mathrm{CA}$, almost all ethanol fuel particles have evaporated. For LPG, due to the smaller momentum of the jet, it is introduced into the cylinder with lower speed. Thus, at $\varphi=140^{\circ} \mathrm{CA}$, there is still a remaining quantity of LPG on the intake manifold.

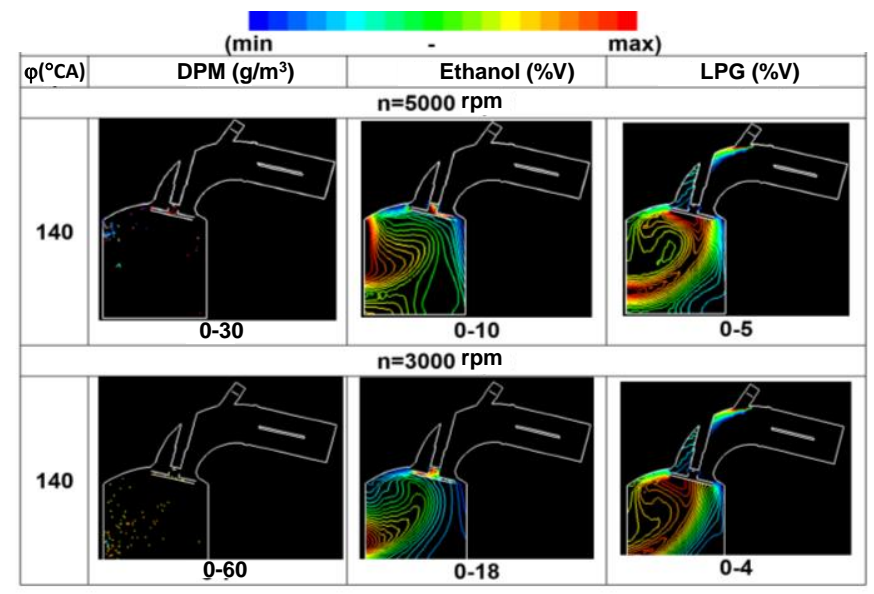

Fig. 2: Distribution of ethanol liquid particles, concentrations of ethanol vapor and LPG in cylinder as engine speed of $5000 \mathrm{rpm}$ and $3000 \mathrm{rpm}$, $\mathrm{BV}=0^{\circ}, \mathrm{T}_{\mathrm{i}}=310 \mathrm{~K}, \mathrm{k}=1, \phi=1$

Due to the momentum of the intake air, the evaporated fuel particles eventually gather in the left-hand side of the cylinder. At the end of the intake stroke, the gas mixture in the cylinder space can be divided into two distinct areas, separated by a layer rich of LPG fuel.

Fig. 3 shows the distribution of the fuel concentration and the velocity field of gas flow at engine speed of $7000 \mathrm{rpm}$. As compared to the case of $\mathrm{n}=3000 \mathrm{rpm}$ and $5000 \mathrm{rpm}$, it can be observed that the engine speed does not significantly affect the distribution of fuel in the cylinder during the intake stroke.

During the compression process, the distribution of the concentration of ethanol and LPG depends on the movement of the gas flow in the cylinder, the ethanol-rich area is on the left-hand side and the LPG-rich area is on the right-hand side of the cylinder. This is due to at the end of the intake process, the remaining ethanol particles occupied the left-hand side of the cylinder. At the moment of ignition, it can be seen that the zone around the spark plug has the optimum equivalence ratio ( $\phi$ is approximately 1). LPG-rich zones are located near the spark plug, while and ethanol-rich zones are found near the cylinder wall (Fig. 4). This is very beneficial for the combustion process. Indeed, ethanol has a high-octane number, so when it is distributed far away from the spark plug, the detonation caused by the increased pressure and temperature of the mixture can be avoided [18]. The stratified distribution of octane number of the fuel mixture in the combustion chamber is an advantage of LPG-ethanol dual injection mode as compared to gasoline-ethanol blend injection mode.

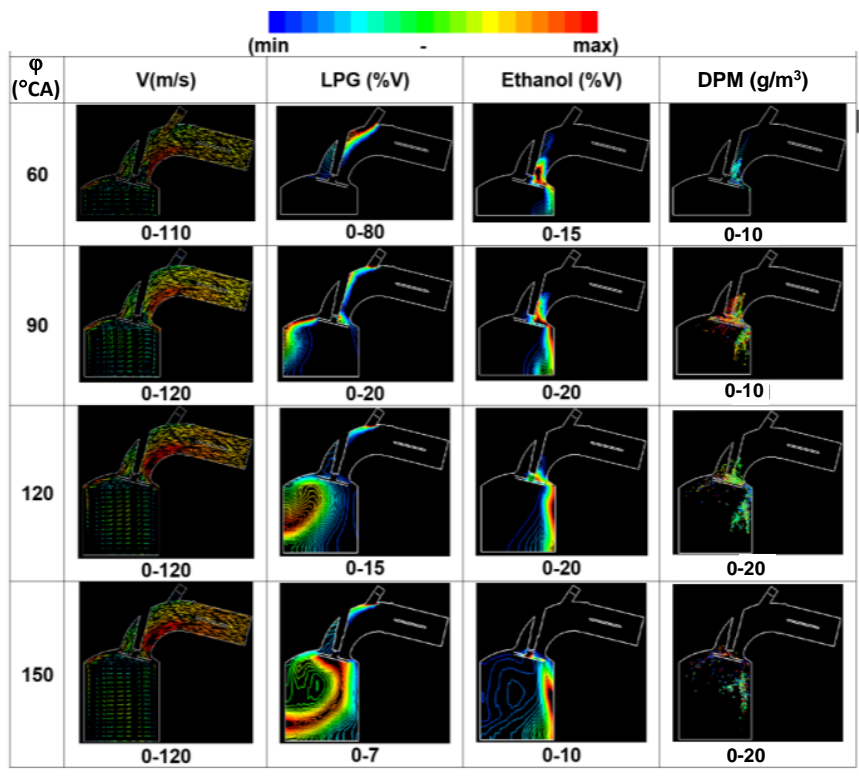

Fig. 3: Distribution of the fuel concentrations and the velocity field of gas flow in the cylinder during the intake process at engine speed of $7000 \mathrm{rpm}$, $\mathrm{BV}=0^{\circ}, \mathrm{T}_{\mathrm{i}}=310 \mathrm{~K}, \mathrm{k}=1, \phi=1$

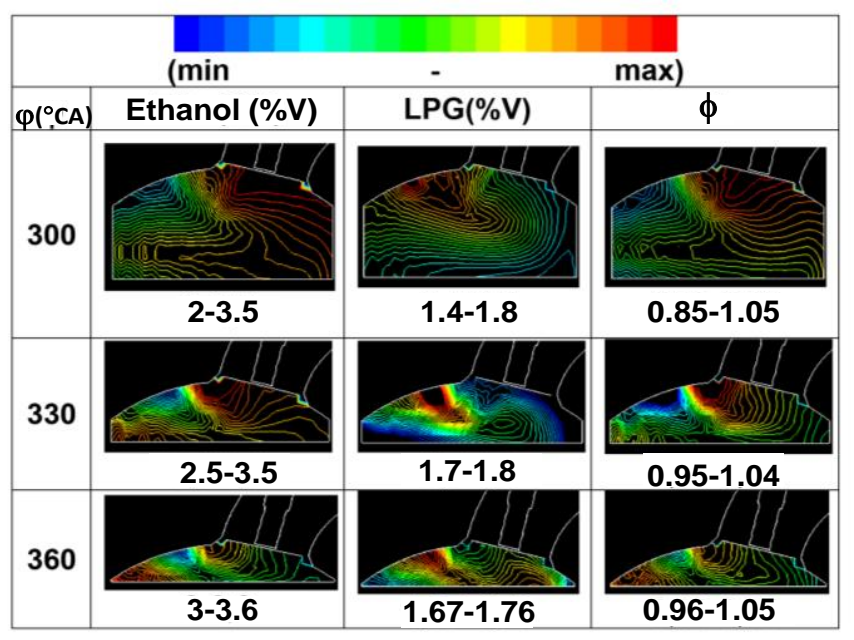

Fig. 4: Distribution of the fuel concentrations and equivalence ratio in the cylinder at the end of compression process at engine speed of $7000 \mathrm{rpm}$, $\mathrm{BV}=0^{\circ}, \mathrm{T}_{\mathrm{i}}=310 \mathrm{~K}, \mathrm{k}=1, \phi=1$ 


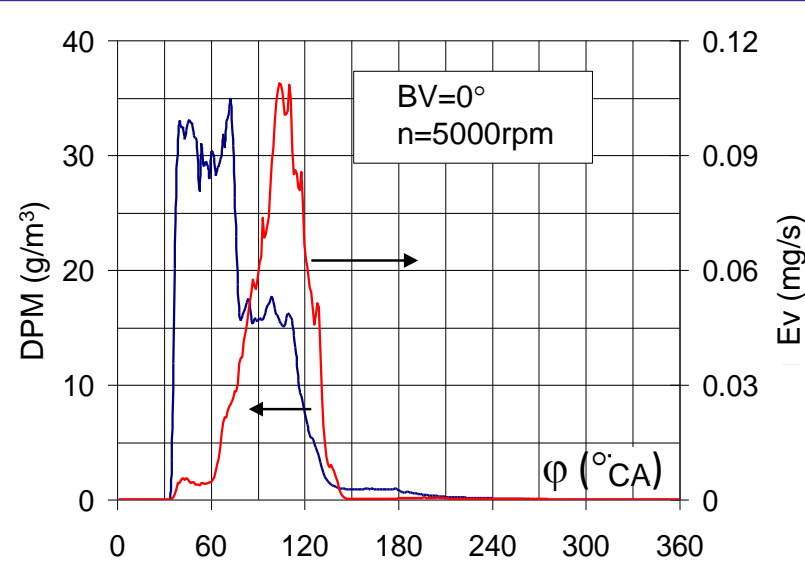

(a)

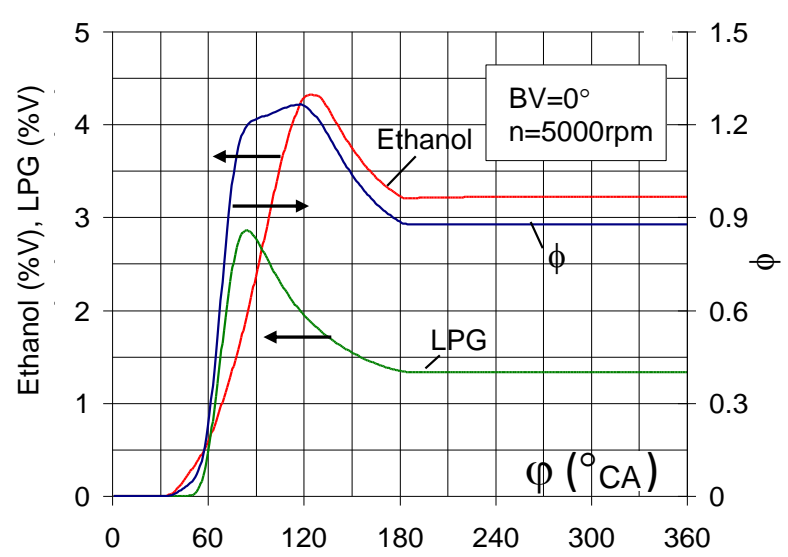

(b)

Fig. 5: Variations of liquid particle density and evaporation rate of ethanol (a); Variation of ethanol concentration, LPG concentration and equivalence ratio (b) with respect to crank angle $\left(\mathrm{BV}=0^{\circ}, \mathrm{n}=5000 \mathrm{rpm}\right)$

Fig. 5a shows the distribution of ethanol liquid particles density and the evaporation rate in the cylinder. It can be observed that the density of liquid particles in the cylinder increases sharply at $15^{\circ} \mathrm{CA}$ after the injection. At about $\varphi=$ $60^{\circ} \mathrm{CA}$, the fuel particles strongly evaporate, reducing the number of particles. The largest particle evaporation rate can be found at $\varphi=100^{\circ} \mathrm{CA}$, then it decreases sharply and tends to 0 at $\varphi=160^{\circ} \mathrm{CA}$. By the end of the intake process, almost all ethanol fuel particles have been completely evaporated. Fig. $5 \mathrm{~b}$, presents the variation of the concentrations of ethanol, LPG, and equivalence ratio with respect to the crankshaft rotation angle. The fuel concentration increases rapidly to about $\varphi=120^{\circ} \mathrm{CA}$. After finishing injection, because the air continues to be introduced into the cylinder, the fuel concentration decreases leading to a decrease in equivalence ratio. When the intake valve is closed, because the ethanol has completely evaporated, the concentrations of ethanol and LPG in the cylinder remain constant, resulting in a stability of equivalence ratio during the compression process.

Fig. 6 presents the variation of equivalence ratio $\phi$ and the coefficient $\mathrm{k}$ according to engine speed when the injection times of LPG and ethanol are kept constant at $0.5 \mathrm{~ms}$ and $0.61 \mathrm{~ms}$, respectively. It can be seen an increase of $\phi$ from 0.59 to 1.05 as the engine speed increases from $3000 \mathrm{rpm}$ to 7000 rpm. Within this range of engine speed variation, the coefficient $\mathrm{k}$ decreases from 1.08 to 0.81 . Thus, it can be seen obviously that when the engine speed increases, the $\phi_{\mathrm{LPG}}$ due to LPG contribution increases. This can be attributed by the increase in vacuum in the intake manifold as increasing of engine speed. The above results also show that $\phi=1$ corresponding to $\mathrm{n}$ approximately $6500 \mathrm{rpm}$ and $\mathrm{k}=1$ corresponding to $\mathrm{n}$ approximately $3500 \mathrm{rpm}$.

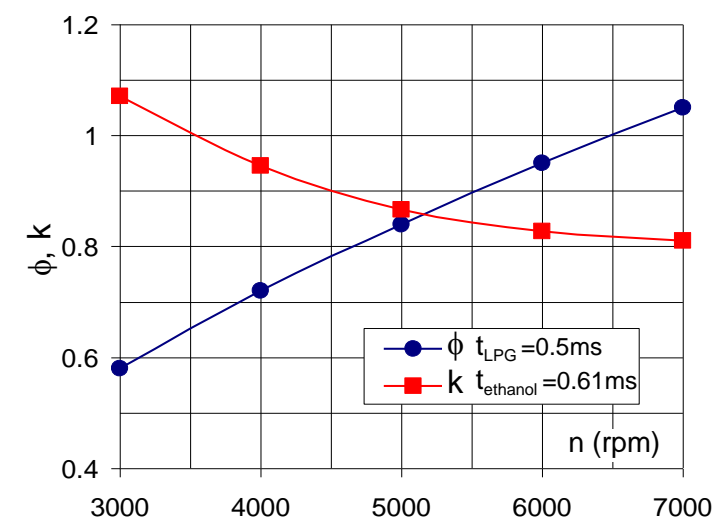

Fig. 6: Variation of $\phi$ and $\mathrm{k}$ in function of crank angle $\left(\mathrm{BV}=45^{\circ}\right)$

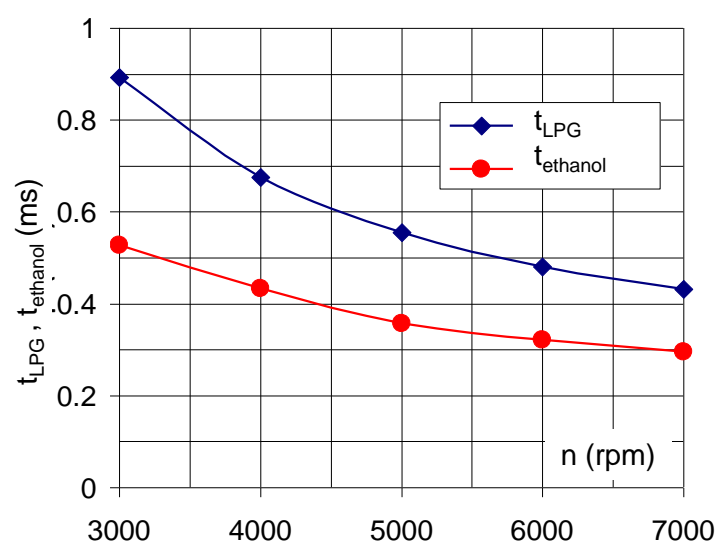

Fig. 7: Variation of injection time of ethanol and LPG with respect to engine speed for $\phi=1$ and $\mathrm{k}=1\left(\mathrm{BV}=45^{\circ}\right)$

Therefore, to maintain the equivalence ratio $\phi=1$ as changing the engine speed, the injection time of LPG and ethanol must be adjusted. Fig. 7 shows the variation of injection time of LPG and ethanol with respect to $n$ to ensure simultaneously $\phi=1$ and $\mathrm{k}=1$. The results show that when the engine speed increases, to ensure $\phi=1$ and $\mathrm{k}=1$ at the same time, the fuel injection time must be reduced. The rate of reduction in injection time of LPG is faster than that of the ethanol, on average.

\subsection{Hybrid powertrain}

\subsubsection{Layout of power sources}

The three-wheel powertrain system consists of two power sources: internal combustion engine and electric motor. The internal combustion engine fueled with LPG-ethanol is converted from Honda $110 \mathrm{cc}$ motorcycle engine as mentioned above. The engine and front frame structure of the original motorcycle is unchanged. This part of the frame is then welded to the rear chassis of the three-wheeler. The torque of the internal combustion engine is transmitted to the rear wheels by chain through a differential as shown in Fig. 8a and Fig. 8b. 


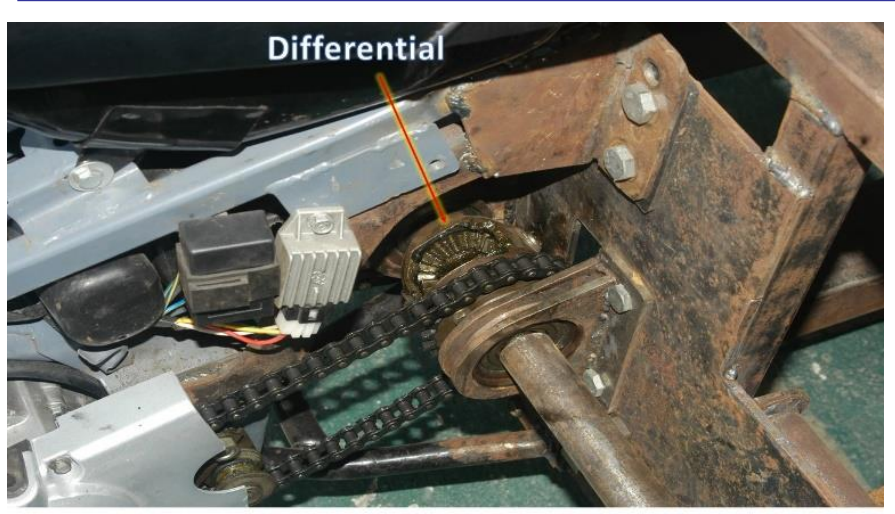

(a)

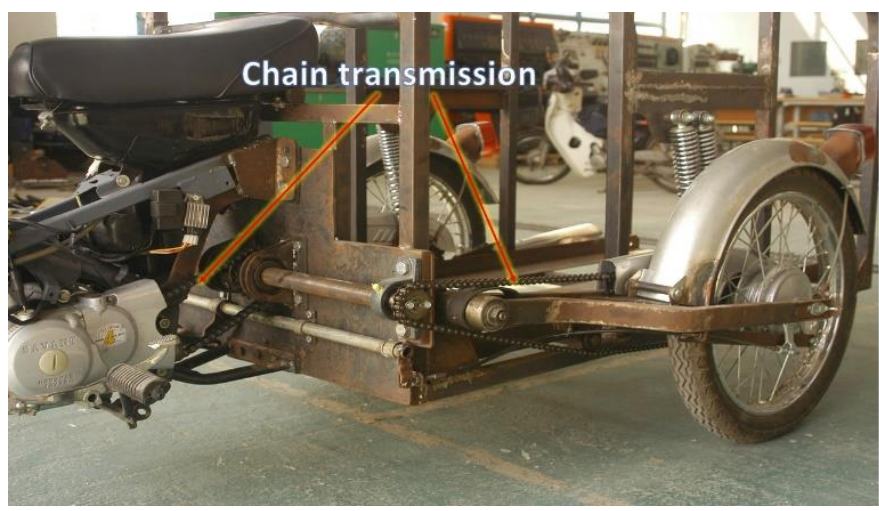

(b)

Fig. 8: Transmission system to the rear wheel: (a) Differential mechanism; (b) Chain transmission mechanism.

The electric motor is integrated into the front wheel of the three-wheeler. The electric motor, wheels, shock absorbers, brakes, control system and fenders are all taken from the electric motorcycle. In order to be able to install the hub electric motor to the front wheel, the front structure of the motorcycle has been modified. Fig. 9 shows the improvement of the front shaft to install the new electric hub motor in the wheel. The electric motor, $1000 \mathrm{~W}$ of power, consumed energy from 4 batteries 12 volts, 20Ah. The batteries are recharged by grid at the parking. During the operation of the three-wheeler, the batteries can be also recharged by the ICE. This is a plugin hybrid mode.

\subsubsection{Control system}

The original motorcycle's electrical system has been improved to ensure that the vehicle can coordinate using the power of the ICE and the electric motor. The basic improvements are as follows:

- Integrating the power control system of the electric motor into the ICE control.

- In electric motor operating mode: disconnect the current through the solenoid valve of the LPG supply system, close the relay to power the electric motor.

- In ICE operating mode: disconnect the relay to supply power to the electric motor, and open the solenoid valve to supply LPG.

- When the car stops: disconnect the entire electrical system.

- The system displays the power coordination mode of the motors.
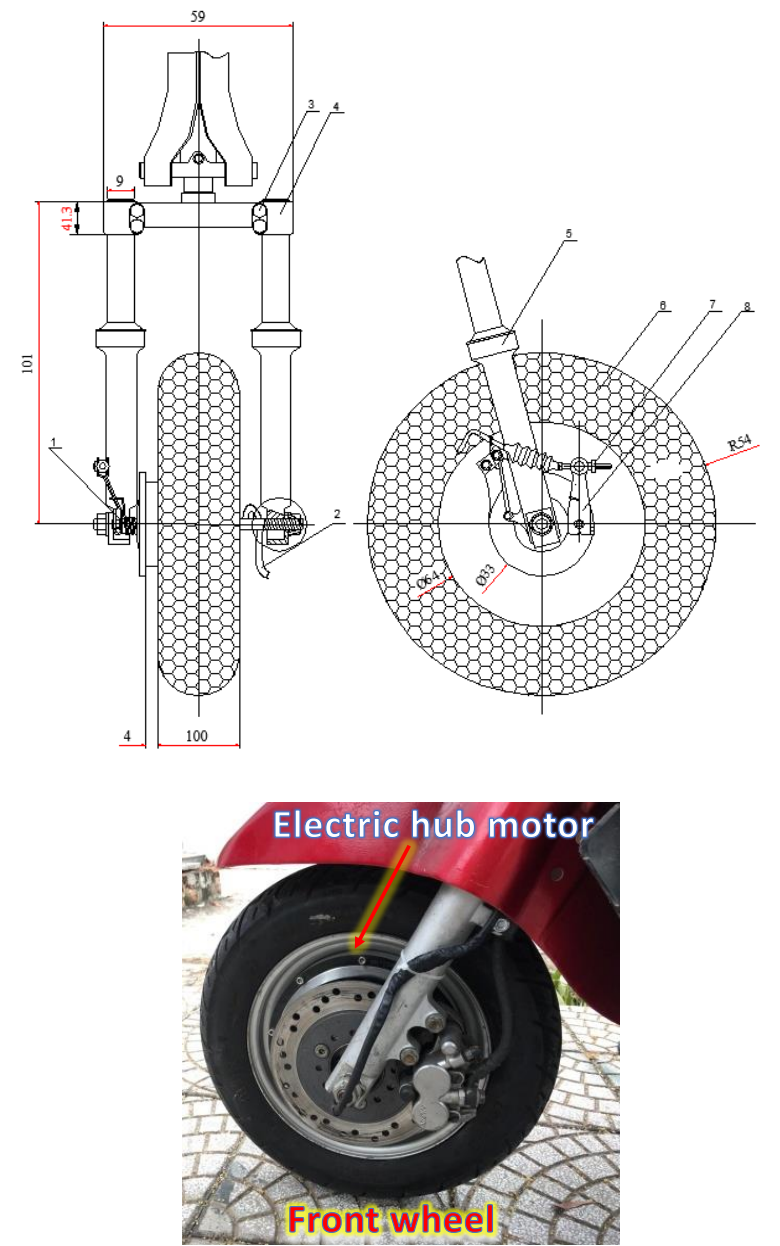

Fig. 9: Integration of electric hub motor into the front wheel

The original circuit diagram of the motorcycle is added a charging circuit, LPG injection and ethanol injection control circuit (Fig. 10a and Fig. 10b), an electric motor control circuit and switching between operating modes as following:

- Only ICE

In this mode, the ICE control system is turn on and electric motor control is turn off. ECM will receive signals from sensors and send fuel injection signal to the microcontroller for controlling the ethanol injector and LPG injector. When the ICE operates, it supplies necessary power for the vehicle and at the same time, generates electricity to recharge the battery.

- Only on electric motor

When the electric motor is switched on and the ICE control is shut down, the motorcycle is powered by electricity. Due to limit of battery capacity, the vehicle can run only $12 \mathrm{~km}$ under this electric driving mode.

- Combination of ICE and electric motor

When high power is needed, both the electric motor and the ICE are in operation. They are controlled by the same accelerator. When the vehicle operates in this mode, the capacity of the electric engine and the ICE engine will be combined to increase the vehicle's overall capacity. 


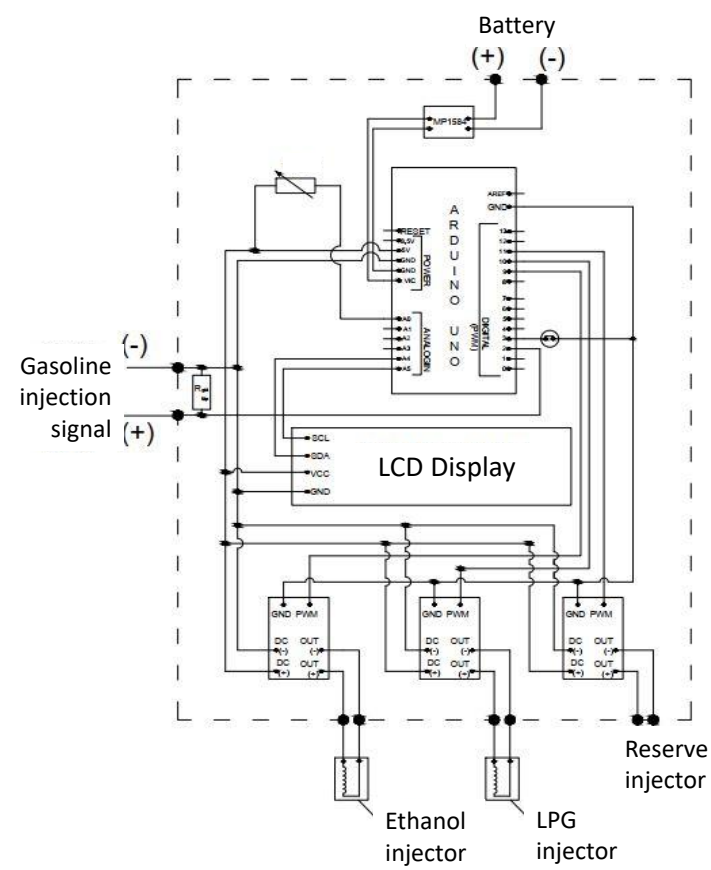

(a)

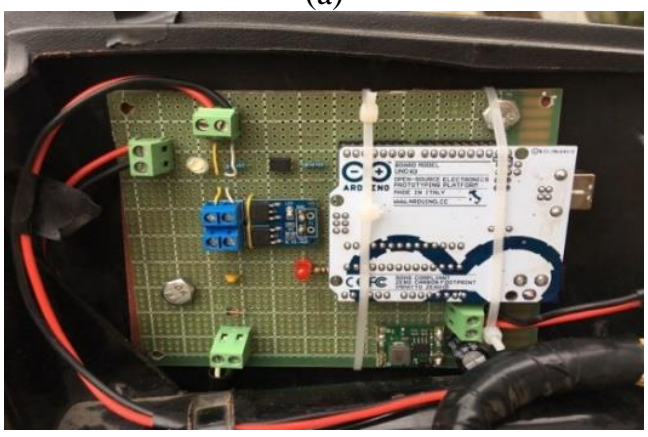

(b)

Fig. 10: Schema of microcontroller for controlling ethanol injector and LPG injector (a) and circuit in practice (b)

\subsubsection{Overall structure of hybrid three-wheeler}

Fig. 11 shows an overall structure of a plug-in three-wheel hybrid motorcycle for goods delivering. Depending on goods transport requirements, the trunk of the three-wheeler can be different designs. In electricity operating mode, the vehicle can run at maximum speed of $36 \mathrm{~km} / \mathrm{h}$. In ICE operating mode, it can reach the maximum speed of $70 \mathrm{~km} / \mathrm{h}$. In full load conditions (vehicle weight $140 \mathrm{~kg}$ and $130 \mathrm{~kg}$ of charge), the vehicle acceleration time from 0 to $32 \mathrm{~km} / \mathrm{h}$ is $40 \mathrm{~s}$. When the batteries are completely depleted, they can be recharged in ICE operating mode. The result show that, when the vehicle runs about $12 \mathrm{~km}$ on ICE mode, the recharging capacity to the battery can provide energy enough for an operating range more than $1.5 \mathrm{~km}$.
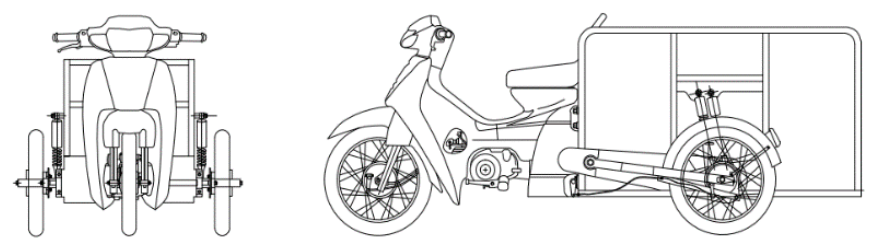

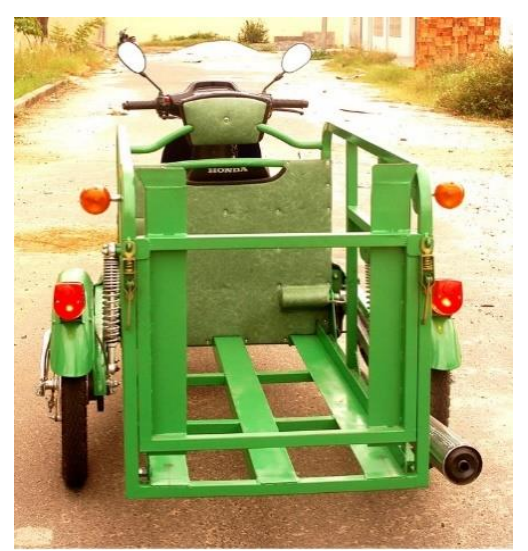

Fig. 11: Overall structure of hybrid three-wheeler

\section{CONCLUSIONS}

The above research results allow us to draw the following conclusions:

- The dual injection of ethanol and LPG creates a stratified mixture distribution in the combustion chamber at the end of the compression process. The relatively rich zone of LPG is found near the spark plug, while the rich zone in ethanol is found near the cylinder wall. This is advantageous for mitigation of the knocking phenomenon.

- With the same throttle opening, in order to maintain the same equivalence ratio, the injection time of LPG and ethanol should be adjusted as the engine speed is variable. When increasing engine speed, to ensure $\phi=1$ and $\mathrm{k}=1$ at the same time, the fuel injection time must be reduced. The rate of LPG injection time reduction is on average higher than that of ethanol injection.

- The LPG-ethanol dual fuel injection system can be converted from the fuel injection system of a conventional gasoline motorcycle. The control signals for ethanol injector and LPG injector can be splitted from the original control signal of gasoline injector with help of a microcontroller.

- The powertrain system of the plug-in hybrid threewheeler can be combined the front part of gasoline motorcycle and a hub electric motor of electric scooter. The LPG-ethanol ICE driving the rear wheels is kept in the position of the original gasoline engine. The electric motor drives the front wheel.

- In full load conditions, the vehicle can run at maximum speed of $36 \mathrm{~km} / \mathrm{h}$ in electricity operating mode and 70 $\mathrm{km} / \mathrm{h}$ in ICE mode. The vehicle acceleration time from 0 to $32 \mathrm{~km} / \mathrm{h}$ is $40 \mathrm{~s}$.

\section{ACKNOWLEDGMENT}

The authors wish to express their appreciation to the Fund for Development of Science and Technology of The University of Danang for supporting this research via the research project B2018-ĐN01-16 "Conversion of a gasoline motorcycle into a hybrid motorcycle."

\section{NOMENCLATURE}

${ }^{\circ} \mathrm{CA}$ : Degree of crankshaft angle

BV : Butterfly valve position $\left(^{\circ}\right)$ 
DPM : Density of liquid particles $\left(\mathrm{g} / \mathrm{m}^{3}\right)$

Ev : Evaporation rate of ethanol $(\mathrm{mg} / \mathrm{s})$

ICE : Internal combustion engine

LPG : Liquefied petroleum gas

n $\quad$ : Engine speed (rpm)

$t_{\text {ethanol }}:$ Injetion time of ethanol

$t_{\mathrm{LPG}} \quad$ : Injection time of LPG

$\mathrm{T}_{\mathrm{i}} \quad$ : Temperature of intake air $(\mathrm{K})$

$\phi \quad$ : Equivalence ratio

$\phi_{\text {ethanol }}$ : Equivalence ratio due to ethanol

$\phi_{\text {LPG }}$ : Equivalence ratio due to LPG

$\mathrm{k} \quad$ : Coefficient of equivalence ratio, $\mathrm{k}=\phi_{\mathrm{ethanol}} / \phi_{\mathrm{LPG}}$

$\varphi \quad$ : Crank angle $\left({ }^{\circ} \mathrm{CA}\right)$

\section{REFERENCES}

[1] M. N. Sasongko, W. Wijayanti and R. A. Rahardja. A Comparative Study of Emission Motorcycle with Gasoline and CNG Fuel. Sustainable Energy and Advanced Materials, AIP Conf. Proc. 1717, 030009-1030009-6; doi: 10.1063/1.4943433.

[2] Bui, V.G. 2001. The Two Wheels Motorcycle Running on Liquefied Petroleum Gas (LPG): A Solution for Urban Air Pollution in Vietnam. 6th ASEAN Science Technology Week, pp. 221, Brunei 17-19 Septembre 2001

[3] Bui, V.G. 2004. Combustion of LPG-air lean mixture and its application on motorcycle engines. The ASEM workshop on EU/ASIA Science and Technology co-operation on clean technology, Hanoi, 3-4 November 2004, pp. 351-359.

[4] Bui, V.G.; Tran, V.N. 2006. Combustion of LPG-Air Lean Mixture: A solution for pollution reduction of motorcycles in Vietnam. The 6th General Seminar of the Core University Program "Environmental Science and Technology for sustainability of Asia", Kumamoto, Japan, 2-4 October 2006, pp. 361-367.

[5] Huang, Y.; Hong, G.; Cheng, X.; Huang, R. 2013. Investigation to charge cooling effect of evaporation of ethanol fuel directly injected in a gasoline port injection engine. SAE paper 2013-01-2610. DOI https://doi.org/10.4271/2013-01-2610.

[6] Boretti, A. 2012. Towards 40\% efficiency with BMEP exceeding 30 bars in directly injected, turbocharged, spark ignition ethanol engines. Energy Convers Manage 57:154-166. DOI: https://doi.org/10.1016/j.enconman.2011.12.011.

[7] Liang C., Ji C., Gao B., Liu X, Zhu Y. 2012. Investigation on the performance of a spark-ignited ethanol engine with DME enrichment. Energy Convers Manage 58:19-25. DOI: https://doi.org/10.1016/j.enconman.2012.01.004

[8] Francesco, C.; Paolo, S.; Bianca, M.V. 2016. Air-fuel mixing and combustion behavior of gasoline-ethanol blends in a GDI wall-guided turbocharged multi-cylinder optical engine. Renewable Energy 96: 319332. DOI: https://doi.org/10.1016/j.renene.2016.04.087.

[9] He, B.Q.; Wang, J.X.; Hao, J.M.; Yan, X.G.; Xiao, J.H. 2003. A study on emission characteristics of an EFI engine with ethanol blended gasoline fuels. Atmos Environ 37:949-57. DOI: https://doi.org/10.1016/S1352-2310(02)00973-1.

[10] Celik, M.B.; Özdalyan, B.; Alkan, F. 2011. The use of pure methanol as fuel at high compression ratio in a single cylinder gasoline engine. Fuel (90):1591-1598. DOI: https://doi.org/10.1016/j.fuel.2010.10.035.

[11] Gong, C,; Liu, Z.; Su, H. et al. 2019. Effect of injection strategy on cold start firing, combustion and emissions of a $\mathrm{LPG} /$ methanol dual-fuel spark-ignition engine. Energy 178:126-133. DOI: https://doi.org/10.1016/j.energy.2019.04.145

[12] Ozcan, H.; Jehad, A.; Yamin, A. 2008. Performance and emission characteristics of LPG powered four stroke SI engine under variable stroke length and compression ratio. Energy Convers Manage 49:11931201
[13] Lanje, A.S. 2017. Effect of Compression Ratio on Performance and Emission Characteristics of LPG-Ethanol Fuelled SI Engine- A Review. International Journal of Engineering and Innovative Technology (IJEIT) 6, Issue 11.

[14] Paolo, I.; Adolfo, S.; Giuseppe, L. Et al. 2016. Effect of ethanol-gasoline blends on $\mathrm{CO}$ and $\mathrm{HC}$ emissions in last generation SI engines within the cold-start transient: An experimental investigation. Applied Energy 179:182-190, DOI: http://dx.doi.org/10.1016/j.apenergy.2016.06.144.

[15] Cetin, M. 2011. The emission of characteristics LPGethanol blend as a fuel in a SI Engine. Energy Education Science and Technology Part A Energy Science and Research 28(1): 151-160.

[16] Lanje, A.S; Deshmukh, M. J. 2012. Performance and Emission Characteristics of SI Engine using LPG-Ethanol Blends: A Review. International Journal of Emerging Technology and Advanced Engineering 2 (10), October 2012

[17] Bui Van Ga, Tran Thanh Hai Tung, Bui Thi Minh Tu, and Bui Van Tan Effects of Ethanol Addition to LPG or to Gasoline on Emissions of Motorcycle Engines Operating Under Urban Conditions. GMSARN International Journal 14(2020) 185-194.

[18] Bui, V.G.; Tran, V.N.; Nguyen, V.D. et al. 2018. Octane number stratified mixture preparation by gasoline-ethanol dual injection in SI engines. International Journal of Environmental Science and Technology. DOI: https://doi.org/10.1007/s13762-018-1942-1. pp.1-14.

[19] Francesco Catapano, Paolo Sementa, Bianca Maria Vaglieco: Air-fuel mixing and combustion behavior of gasoline-ethanol blends in a GD wall-guided turbocharged multi-cylinder optical engine. Renewable Energy 96 (2016) 319-332.

[20] Rahman, M.A. 2018. Induction of hydrogen, hydroxy, and LPG with ethanol in a common SI engine: a comparison of performance and emission characteristics. Environmental Science and Pollution Research. DOI: https://doi.org/10.1007/s11356-018-3861-6. 